\title{
Comparative Analysis of Hardness Performance of a 7075 Aluminum Alloy Having Carbon Fiber and Carbon Nanotubes
}

Raul Pérez-Bustamante ${ }^{1}$, Fernando Pérez-Bustamante ${ }^{2}$, Felipe Avalos-Belmontes ${ }^{2}$, Juan Ramos-Cano ${ }^{2}$, Hugo Arcos-Gutierrez ${ }^{3}$, Luis Alberto Caceres-Diaz ${ }^{4}$, John Edison Garcia-Herrera ${ }^{4}$ and R. MartínezSánchez ${ }^{5}$

${ }^{1}$ Corporacion Mexicana De Investigacion en Materiales, San Luis Potosi, San Luis Potosi, Mexico, ${ }^{2}$ Universidad Autonoma de Coahuila, Saltillo, Coahuila de Zaragoza, Mexico, ${ }^{3}$ CONACYT-Centro de Tecnologia Avanzada, San Luis Potosi, San Luis Potosi, Mexico, ${ }^{4}$ Centro de Tecnologia Avanzada, San Luis Potosi, San Luis Potosi, Mexico, ${ }^{5}$ Centro de Investigación en Materiales Avanzados (CIMAV), Laboratorio Nacional de Nanotecnología, Chihuahua, Chihuahua, México

The mechanical characteristics of different carbon structures are of scientific and engineering interest for applications where lightness and strength are required for the synthesis of advanced materials and the manufacturing of novel components [1]. However, among the materials used as reinforcement in the synthesis of composites, must be considered those with high intrinsic mechanical properties and with the capability of being synthesized in a massive way at low cost. Carbon fiber is now being extensively used in the automotive and aeronautic industry with excellent results in the production of micro- and macrocomposites [2]. On the other hand, in the nanoscale, an interesting allotropic form of carbon with promising results in the production of novel composites, are carbon nanotubes.

For this purpose, the aluminum 7075 commercial alloy was reinforced by the addition of carbon fibers (CF, Fig. 1a, b) and carbon nanotubes (CNT Fig. 1c, d). The CF and the CNT concentration was set to 5.0 wt.pct. The milling time was set to $5 \mathrm{~h}$. Composites were produced by mechanical alloying (MA) in a high energy mill Spex 8000M. The powder mass was $8.5 \mathrm{~g}$ and the ball-to-powder ratio was of 5:1. All milling runs were performed with methanol as a process control agent (PCA). Argon was used as inert milling atmosphere. An unmodified Al7075 alloy milled under the same conditions was used as reference.

The characterization of the microstructure of the samples, was performed by scanning electron microscopy (SEM) in a JEOL model JSM-7401F operated at $5 \mathrm{kV}$. Transmission electron microscopy (TEM) observations were carried out in a JEOL JEM 2200FS operated at $200 \mathrm{kV}$. Specimens for TEM characterization were prepared by focusing ion beam (FIB) in a JEOL model JEM-9320FIB equipped with a nano-manipulator Omniprobe 200 and operated at $30 \mathrm{kV}$.

The mechanical behavior of composites was evaluated by hardness and measured using a micro hardness tester model FutureTech ( $200 \mathrm{~g}$ of load, $15 \mathrm{~s}$ of dwell time). The average value of at least 10 indentations is reported.

Bright field TEM micrographs shown in Fig. 1 (e,f) confirm the absence of carbide nanoparticles. It can be observed the presence of two different structures in the aluminum matrix, which depict the corresponding carbon structures associated to the $\mathrm{CF}$ and the $\mathrm{CNT}$ s respectively. Fig. 1e shows amorphous arrays of carbon atoms corresponding to the $\mathrm{CF}$, whilst Fig. 1f shows a CNT embedded in the aluminum matrix. A small degree of structural damage can be observed on the outer walls of the CNTs, which can be attributed to the mechanical alloying process, as it has been previously observed [3]. Although, $\mathrm{CF} / \mathrm{Al} 7075$ composites present an inferior mechanical performance to the observed by the CNT/A17075 composites (Fig. 2), the possibility of preserving the lamellar structure in the milled powders, considering 
rapid sintering methods, extends their applications for MA composites, even using less expensive material reinforcements, such in this case is the use of carbon fibers [4].
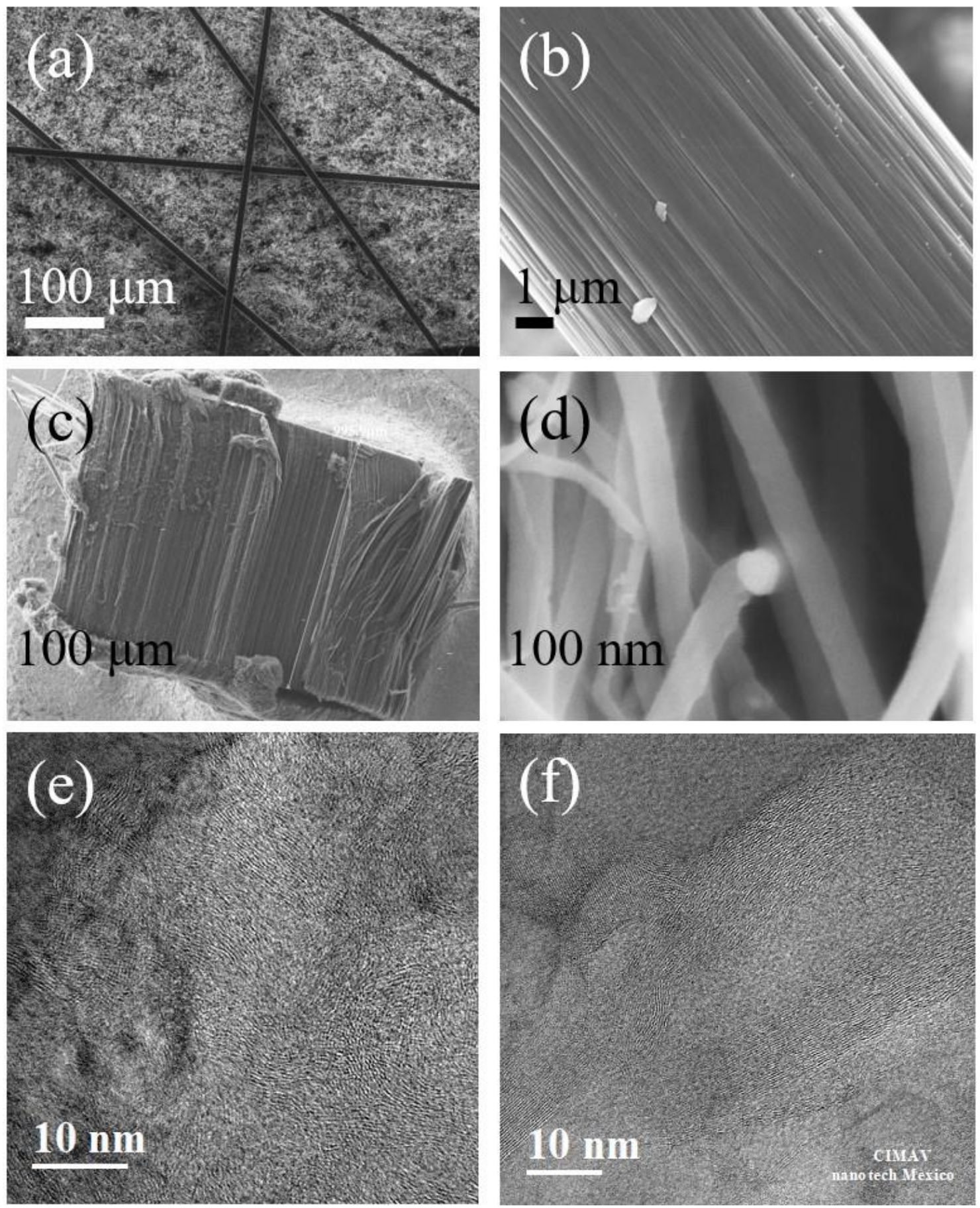

Figure 1. Electron micrographs of the morphology of $(\mathrm{a}, \mathrm{b})$ carbon fiber, $(\mathrm{c}, \mathrm{d})$ carbon nanotubes and the aluminum composite reinforced with (e) carbon fiber and (f) carbon nanotubes 


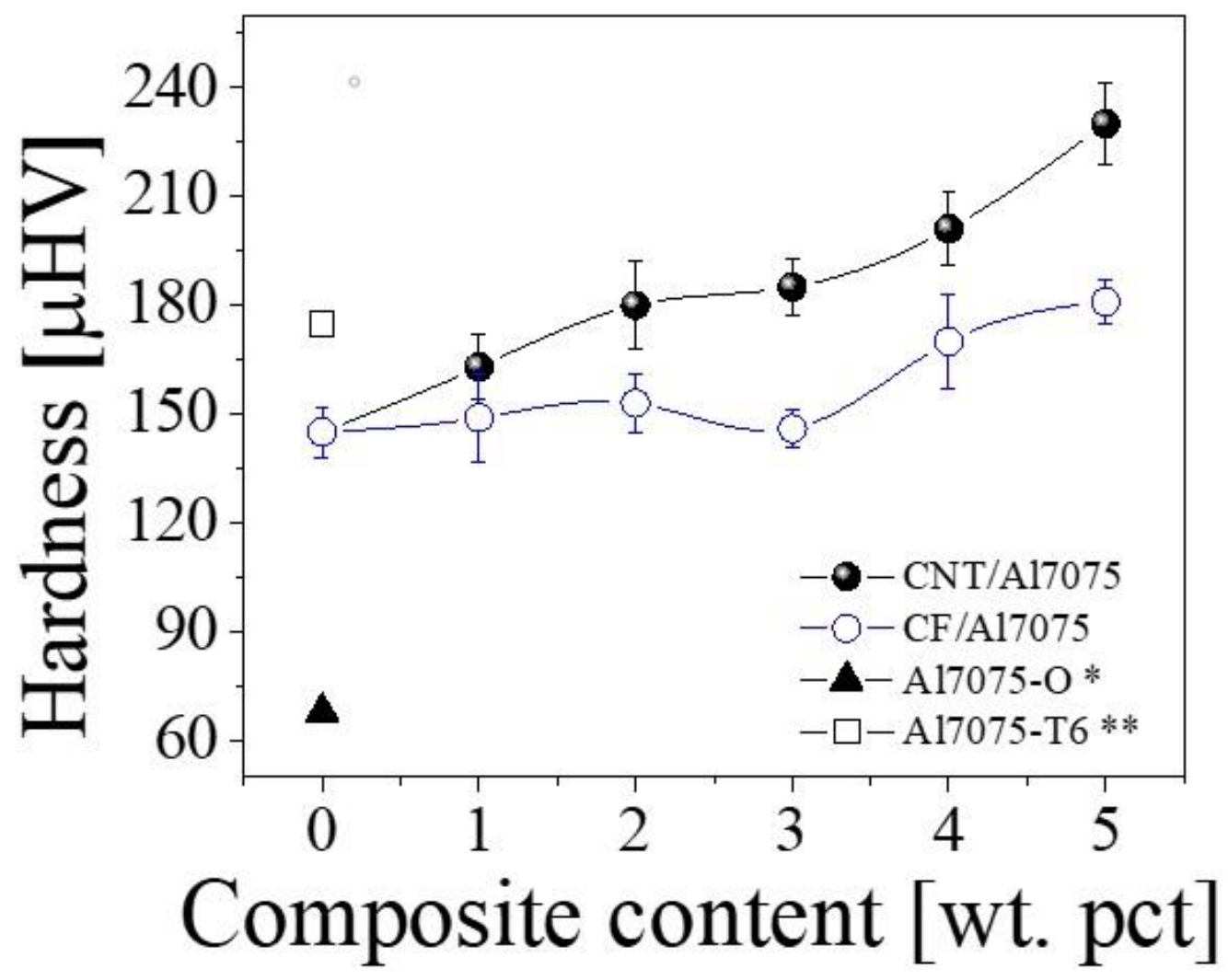

Figure 2. Hardness results of composites reinforced with carbon fiber and carbo nanotubes

References

1. M. Jagannatham, et al. Carbon, 160 (2020), p14.

2. H. Carter, Reinforced Plastics, 64 (2020), p 57.

3. R. Pérez-Bustamante, et al. Materials characterization, 126 (2017), p28.

4. R. Pérez-Bustamante, H. Arcos-Gutierrez, LA. Cáceres-Diaz and JE. García-Herrera are grateful with the program Cátedras CONACYT (Projects 850 and 674) for their support. 